\title{
Risk-taking and behavioral inhibition interaction in ADHD- with and without conduct disorder- compared with control children
}

\author{
Soroush Nasri $^{1}$, Mohammad Ali Nazari ${ }^{2}$, Ehsan Maiqani ${ }^{3}$, Hassan Shahrokhi ${ }^{4}$, Iraj Goodarzi ${ }^{5}$ \\ 1-M.Sc. child and adolescent clinical psychology, University of Tabriz, Tabriz, Iran. ORCID: 0000-0003-4337-2149 \\ E-mail: sqinasri@gmail.com \\ 2- Associate Professor, department of Psychology, cognitive neuroscience laboratory, University of Tabriz, Tabriz, \\ Iran. ORCID: 0000-0002-0340-9994 \\ 3- M.Sc. Computer science department, University of Tabriz, Tabriz, Iran. ORCID: 0000-0002-7106-5317 \\ 4- Psychiatrist, Research center of psychiatry and behavioral sciences, Tabriz university of medical science. Tabriz, \\ Iran. ORCID: 0000-0003-3640-5344 \\ 5- Psychiatrist, Shahrekord University of Medical Sciences, Sharekord, Iran. ORCID: 0000-0002-9047-9304
}

Received: 28/06/2018

Accepted: 21/10/2018

\begin{abstract}
Introduction: Attention deficit/hyperactivity disorder is associated with impulsivity and behavioral inhibition deficits, Risk taking is the important aspect of impulsive behavior.

Aim: The purpose of this study was to Comparison of risk-taking regarding behavioral inhibition deficits in attention deficit hyperactivity disorder (ADHD) with and without conduct disorder (CD) and compared with control children.
\end{abstract}

Method: 37 male children with ADHD (23 ADHD only and 14 ADHD with conduct disorder (ADHD+CD)) were selected by purposive sampling method and performed Balloon Analog Risk Task (BART) and Go-Nogo task to measure risk taking and behavioral inhibition, and compared with 18 normal children. The data was analyzed by ANOVA, MANOVA and MANCOVA.

Results: Data analysis demonstrated that ADHD+CD group has the highest risk taking followed by ADHD and control group without considering of behavioral inhibition; although comparing to control group, ADHD+CD group has meaningless difference by arranging behavioral inhibition deficits, even though ADHD group has the same risk taking scores in compared with control group both considering behavioral inhibition deficits.

Conclusion: This finding suggested that ADHD children have impulsivity because of behavioral inhibition deficits, while it would not be able to predict destructive behavior and risky activities in ADHD+CD in compared with ADHD by itself, also it could be a high risk taking pattern.

Keywords: Attention- deficit Hyperactivity Disorder, Conduct disorder, behavioral inhibition deficits, risk taking

How to cite this article : Nasri S, Nazari M A, Maiqani E, Shahrokhi H, Goodarzi I .Risk-taking and behavioral inhibition interaction in ADHDwith and without conduct disorder- compared with control children. Shenakht Journal of Psychology and Psychiatry. 2018; 5 (4): 63-77 .

URL :http://shenakht.muk.ac.ir/article-1-494-fa.pdf

Copyright $@ 2018$ the Author (s). Published by Kurdistan University of Medical Sciences. This is an open access article distributed under the terms of the Creative Commons Attribution-Non Commercial License 4.0 (CCBY-NC), where it is permissible to download, share, remix, transform, and buildup the work provided it is properly cited. The work cannot be used commercially without permission from the journal. 


\title{
تعامل خطريذيرى و بازدارى رفتارى در اختلال نارسايى توجه / بيش فعالى با و بدون اختلال

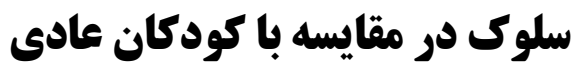

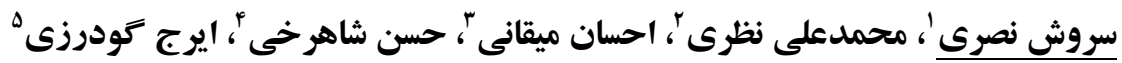

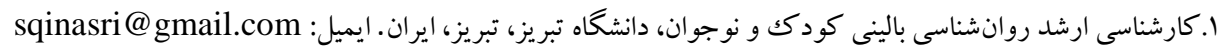

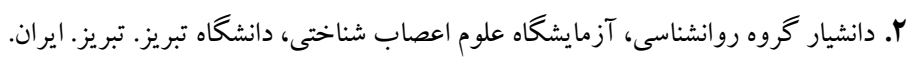

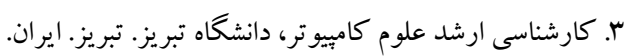

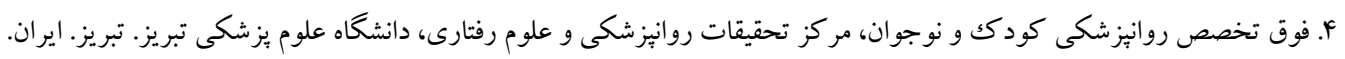

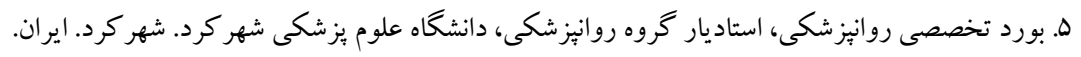

مقدمه: اختلال نارسايى توجه / بيشفعالى با تكانشخرى و نقص در بازدارى رفتارى همراه است، خطريذيرى نيز به عنوان جنبهى مهمى از رفتار تكانشخر انه شناخته مى شود. هدف: هدف يُزوهش حاضر، مقايسه ميزان خطريذيرى با در نظر گرفتن علائم بازدارى رفتارى در كودكان داراى نشانهاى نارسايى

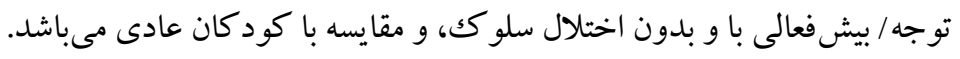

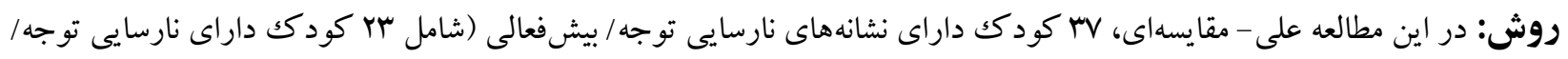

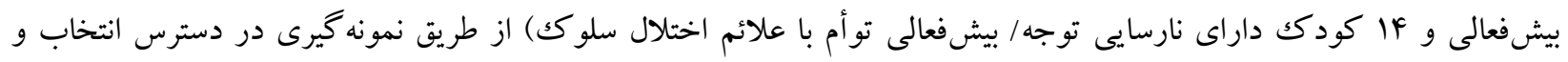

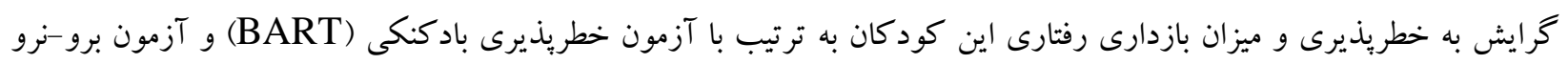
(Go-Nogo)

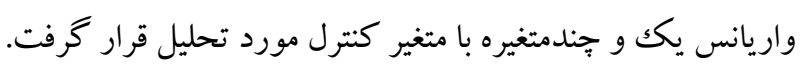
يافته ها: نتايج نشان داد، كود كانى كه علاوه بر ADHD نشانهاى اختلال سلو كك را دارا هستند، بيش از كنترل نقايص بازدارى

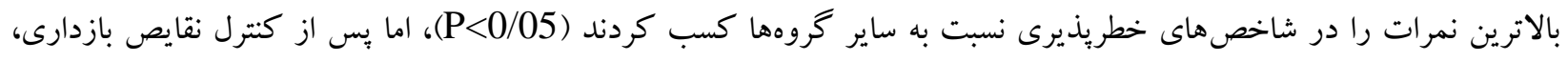

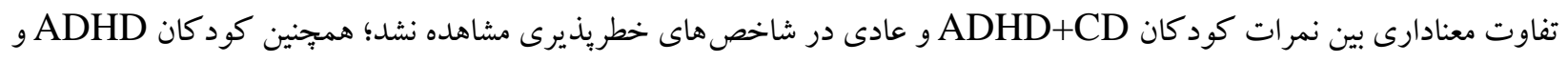
عادى ييش و يس از كنترل نقايص بازدارى رفتارى، در شاخص هاى خطريذيرى تفاوت معنادارى نداشتند.

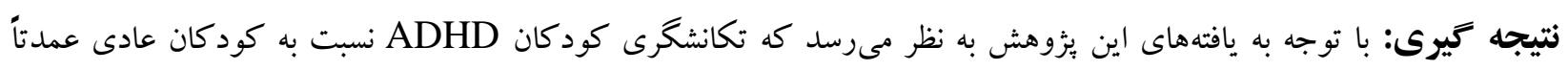

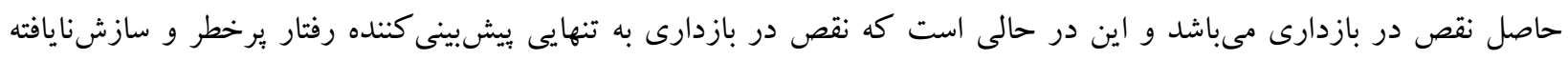

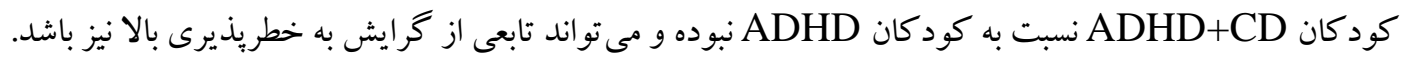

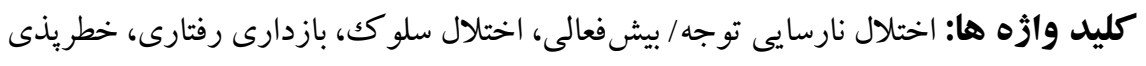


مهمى در رشد بهنجار و نابهنجار ايفا مى كند (نيگك، مقدمه

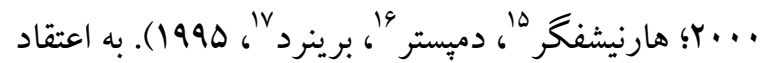

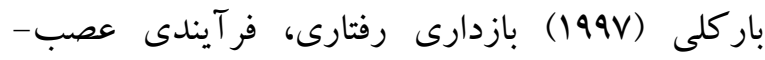
شناختى است كه به كود كان كمكك مى كند تا درنگيدهتر رفتار كنند. باركلى بر اين باور است كه بازدارى رفتارى باعث مىشود ياسخدهى به يكك رويداد با تأخير انجام شده و فرصتى را ايجاد مى كند تا فرايند خودكنترلى (خودنظمجويى) عمل كرده و اعمال خودفرمان شكل

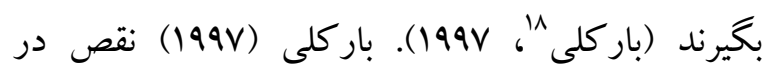
بازدارى رفتارى را به عنوان نقص مركزى در نارسايى ليى توجه/ بيش فعالى مطرح كرد. نارسايى توجه / بيشفعالى

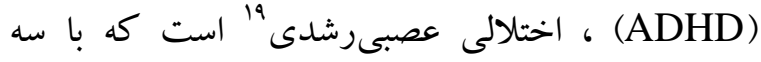
ويز گى اصلى يعنى نقص توجه، بيشفعالى و تكانشخرى

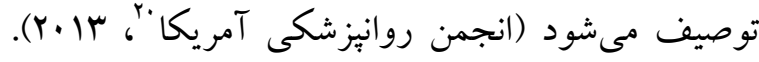
نقص در بازدارى به عنوان يكك نابهنجارى مركزى در ADHD

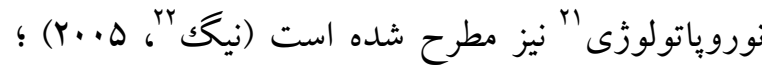
مطالعات متعدد شواهدى را مبنى بر نقص در بازدارى

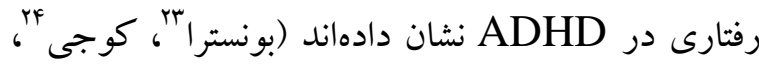

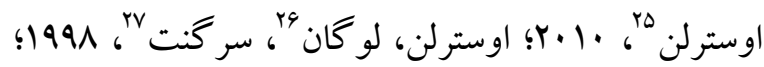

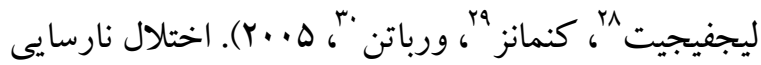
توجه بيشفعالى به عنوان يك عامل تهديدكننده براى

\footnotetext{
${ }_{16}^{15}$ Harnishfeger

${ }_{17}^{16}$ Dempster

${ }_{18}^{17}$ Brainer

19 neurodevelopmental

${ }_{21}^{20}$ American Psychiatric Association

neuropathology

$23{ }^{\text {nigg }}$

24 Kooij

${ }_{26}^{25}$ Oosterlaan

${ }_{27}^{27}$ Logan

${ }_{28}^{2}$ Lijffijt

${ }^{30}{ }_{\text {Verbaten }}^{29}$
}

تكانشخرى'هسته اصلى بسيارى از آسيبهاى اجتماعى مانند سوءمصرف مواد، قماربازى بيمار گون، اختلالات بلات شخصيت و دست زدن به اقدامات برخاشجويانه است (اختيارى، صفايى، اسماعيلى جاويد، عاطفوحيد،

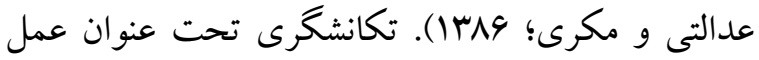
نمودن با كمترين تفكر نسبت به رفتارهاى آينده يا عمل كردن بر بايهى افكارى كه بهترين گزينه فرد يا ديخران

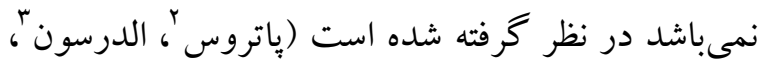

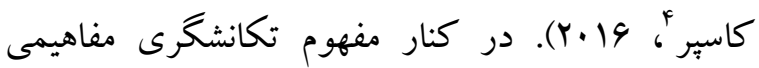

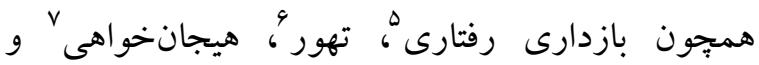

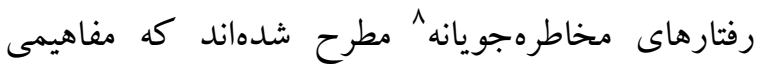

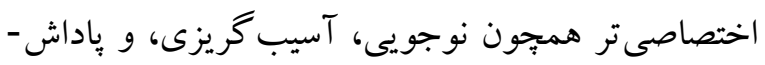

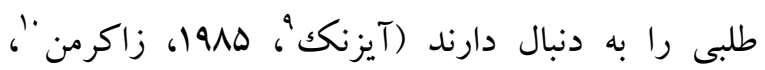

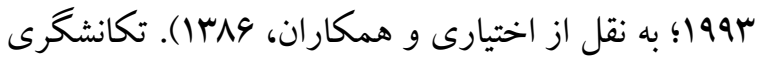
اغلب با آسيبهاى روانى در سطوح فردى و اجتماعى همراه است كه خشونت، رفتارهاى ضداجتماعى، جرم و

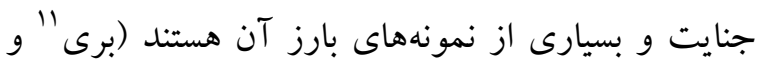

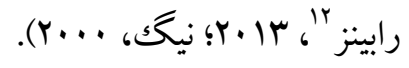

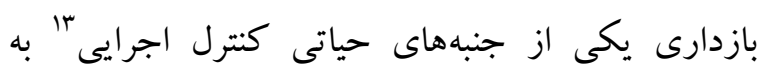

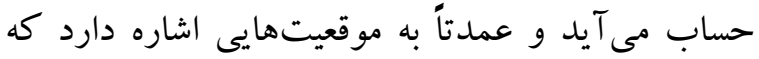
مستلزم اقدامات صحيح و همجنين كنترل و متوقف

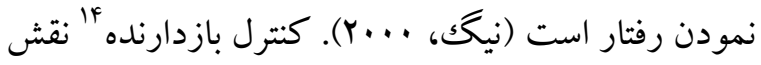

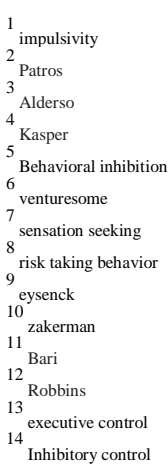


احتمال و عدم قطعيت همراه است (نجاتى و شيرى،

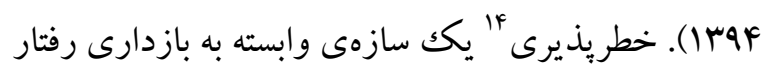
است و كرايش نسبت به رفتار منفى كه سلامت، رفاه و طول عمر را مورد تهديد قرار مىدهد اشاره دارد

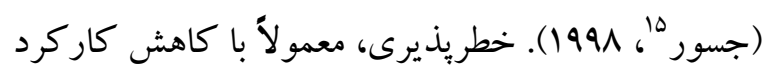
در ساختارهاى تنظيم شناختى از جمله كورتكس بيش -

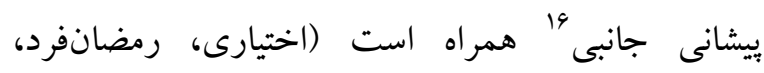
مكرى، IMAV) امروزه در مجامع علمى، كليهى مفاهيم

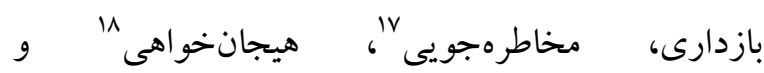
تكانشخرى19 در كنار تصميم گيرى مخاطرهآميز مطرح شدهاند كه همكى بحث در مورد سوءمصرف مواد، جامعهستيزى، سايكوياتى، خشونت، جرم و جنايت و ول، بسيارى ديخر از معضلات اجتماعى رادر ذهن متبادر مى - سئسئ سازند.

اختلال سلوك مجموعهى پايدارى از رفتارهايى است كه با كذشت زمان شكل كرفته و غالباً مشخصهى آن برخاشگرى و تجاوز به حقوق ديخران است. كودكان دجار اختلال سلوكك ممكن است در جهار زمينهى: يرخاشخرى جسمانى يا تهديد صدمه به ديخران، تخريب اموال ديخران يا خود، دزدى يا فريبكارى و نقض مكرر قواعد متناسب با سن رفتارهايى بروز دهند (انجمن

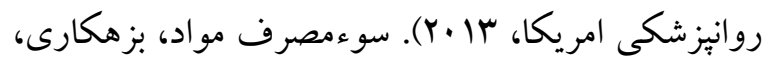
وسواس بيمارگون آتشافروزى، مىبارگى و خشونت،

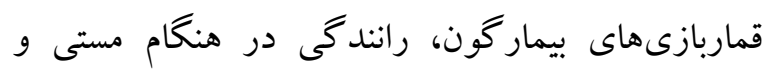
رفتارهاى جنسى برتنش نمونههايى از رفتارهاى برخطر

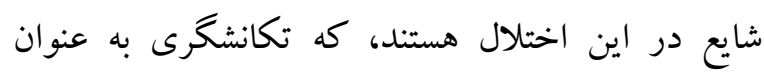

بروز اختلال سلوكك' و رفتارهاى ضداجتماعى در

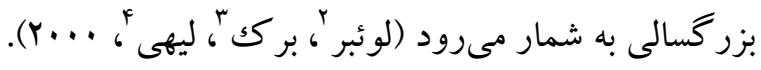
I Y Y Y...

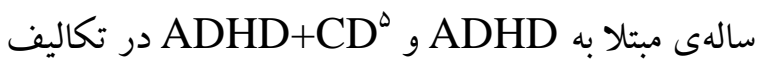
تكاليف برو- نرو و و توقف نشانه (دو تكليفى كه به طور طور اختصاصى توانايى بازدارى را اندازه گيرى مى كنند)

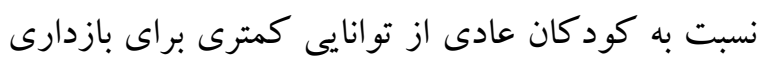

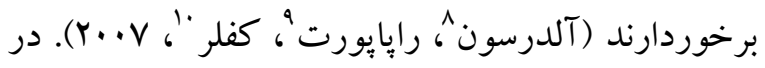

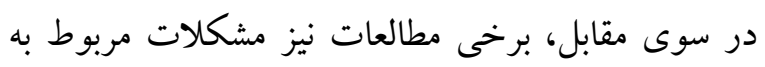
بازدارى رفتارى در ADHD را گزارش نكردهاند

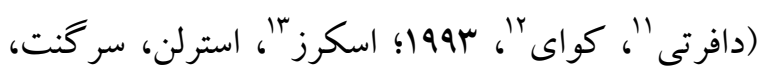

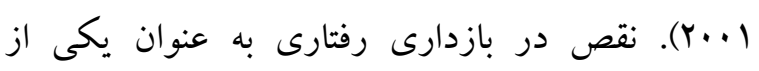

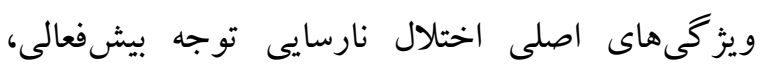

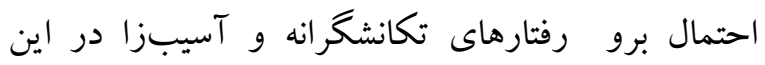
كود كان را افزايش داده است.

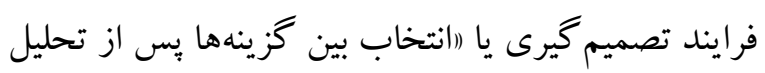

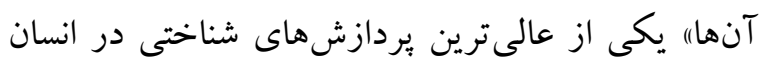

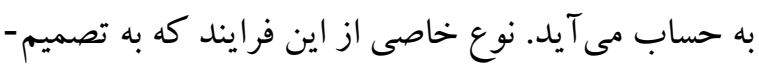

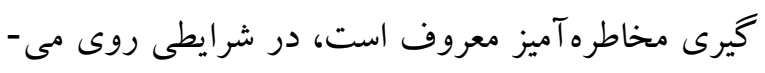
دهد كه شخص با گزينهايى مواجه مى گردد كه انتخاب آنها بارى از سود و زيان را در حال و آينده به همراه دارد و در عين حال، ميزان اين سود و زيان با درجاتى از

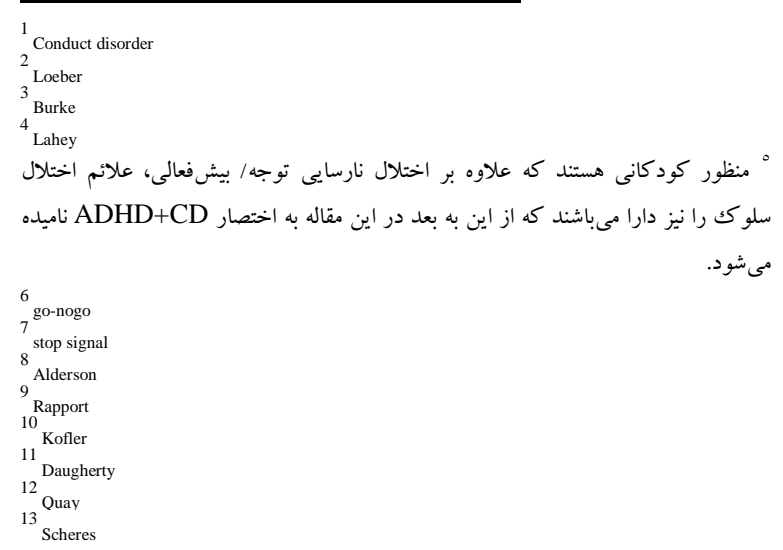


در تبيين بديده تكانشخرى و رفتارهاى مخاطرهجويانه در اختلالات برونىسازىشده كود كان، مفاهيم بازدارى ليّى رفتارى (ياتروس و همكاران، 19 19؟؛ باركلى، 199V؛

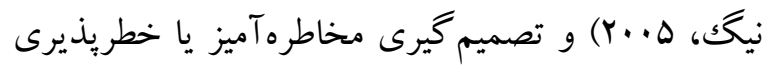

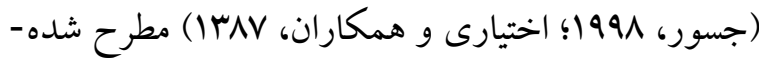
اند. با اين حال، نكتهاى كه در اين ميان وجود دارد اين است كه كودكان ADHD سطوح مختلفى از تكانشخرى را (از درگيرى با همسالان، تا سرقت و سوءمصرف مواد در سنين پايين) بروز مىدهند، بدونشكك احتمال بروز رفتارهاى تكانشخرانه و آسيبزا در كودكان ADHD+CD بيشتر است. با اين حال، ادبيات يثزوهشى حاكى از نقايص بازدارى يكسان در هر دو گروه

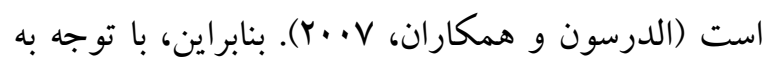

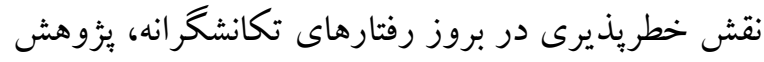
حاضر به بررسى نقش اين سازه در بروز رفتارهاى

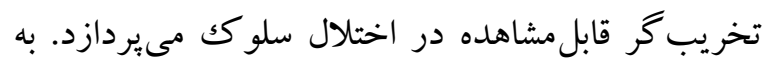
عبارت ديخر، يزوهش حاضر بر آن است كه با مقايسهى نشانهاى خطريذيرى به عنوان يكك عامل براى بروز

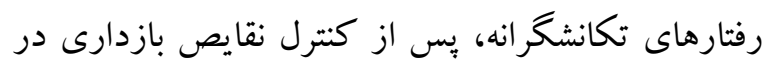
اختلالات ADHD و ADHD+CD مشخص سازد كه آيا كرايش به خطريذيرى مىتواند به عنوان يك سازهى مستقل در سير اختلال نارسايى توجه/ بيشفعالى به سمت اختلال سلو كك نقش داشته باشد؟

طرح يثوهش حاضر از نوع على-مقايسهاى و روش نمونه گيرى نيز به صورت در دسترس بود. به اين صورت

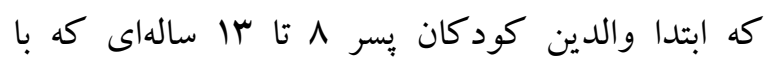
شكايت اصلى علائم ADHD به كلينيك ارجاع داده مىشدند، يس از دريافت تشخيص ADHD از نوع
هستهى اصلى بروز اين رفتارها در طيف گستردهاى از اين اختلالها در كود كان، نوجوانان و بزر گسالان به شمار مى آيد (اختيارى، رمضانفرد و مكرى، MNVV). عليرغم اين كه تفاوتهاى فردى نقش قابلتوجهى در ميزان خطريذيرى كود كان و نوجوانان دارد (لجوئز '، آكلين'،

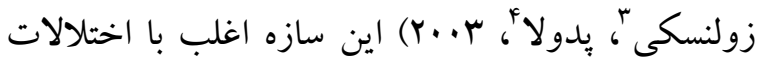

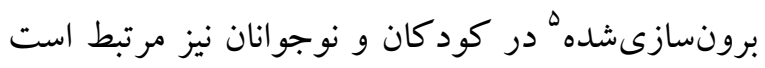

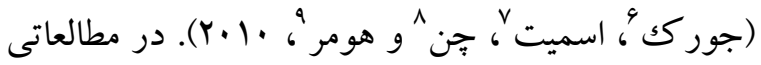
مطالعاتى كه تصميم گيرى را از طريق آزمون قمار "' مورد سنجش قرار دادهاند ميزان بالاى خطريذيرى و حساسيت

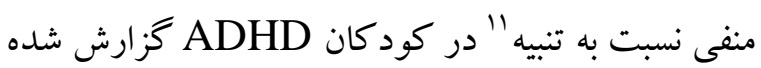

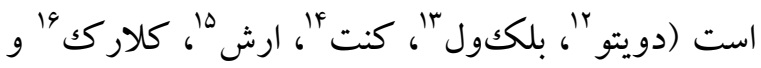

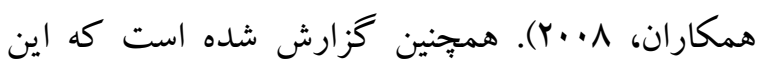
كود كان به لحاظ رفتارى كمتر تحت تاثير تنبيه قرار مى -

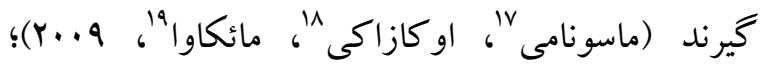
كرجه در بررسى رابطهى بين خطريذيرى و ADHD، اختلالات برونىسازىشده همبود از جمله بىاعتنايى مقابلهاى ‘r و اختلال سلوكك (CD) كنترل نشدهاند

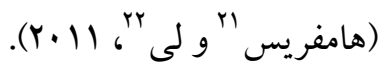




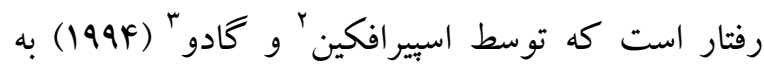
منظور غربال اختلالات رفتارى و هيجانى در كودكان سنين ه تا Y I سال طراحى شده است. اين برسشنامه داراى

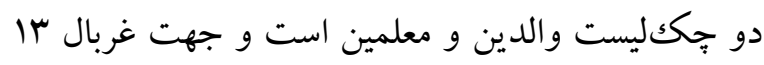
اختلال رفتارى و هيجانى طراحى شده است. هر يكك از عبارات مذكور در يك مقياس F درجهاى: (اهركز، كاهى، اغلب و بيشتر اوقات) باسخ داده مىشود. تعداد

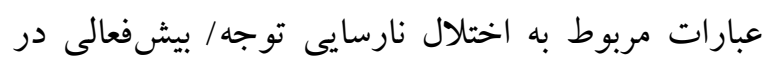
CSI-4 تعداد عبارات ها مورد مىباشد. از اين برسشنامه جهت سنجش علائم اختلال نارسايى توجه / بيشفعالى، اختلال سلوكs و علائم مرضى احتمالى ديخر در كودكان

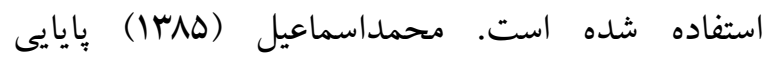
بازآمايى براى اختلال نارسايى توجه/ بيشفعالى نوع

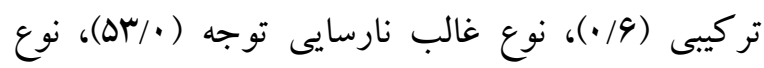
غالب تكانشخرى-بيش فعالى ( • (99) خزارش كرده است، همجينين اعتبار همسانى درونى با استفاده از آلفاى كرونباخ در اين سياهه براى بيشفالى /نارسايى توجه نوع

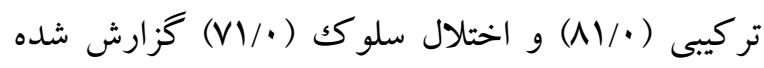

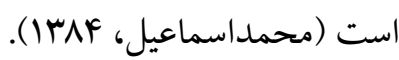
آزمون ماتريسهاى بيشرونله ريون: در بيزوهش حاضر جهت كنترل عامل هوش از نسخه رايانهاى اين آزمون كه توسط مركز مشاوره و خدمات روانشناسى رازى، به سفارش سازمان آموزشويرورش منطقه ياكدشت تهيه و ساخته شده است استفاده گرديد، كودكانى كه در اين آزمون بهره هوشى كمتر از له نشان مىدادند، از ادامهى

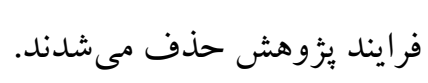

مركب و يا ADHD+CD از سوى روانيزشك، يرسشنامهى علائم مرضى كودكان CSI-4 را تكميل مىنمودند. كود كانى كه در مشكلات ADHD نمرهى بالينى دريافت كردند در گروه ADHD و كود كانى كه علاوه بر آيتمهاى ADHD در سؤالات مربوط به مشكلات سلوكى نيز نمرهى بالينى دريافت نمودند در كروه ADHD+CD قرار كرفتند؛ به شرطى كه بـ تشخيص روانيزشكى نيز اين امر را تأييد مى كرد. البته

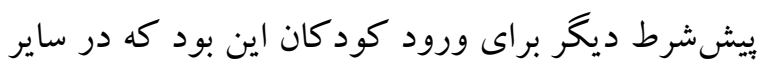
مقياس هاى CSI-4 حائز نمرهى بالينى براى هيتج اختلالى لئ نباشند. كودكان گروه كنترل نيز از بين جمعيت غير كلينيكى انتخاب شدند. به اين صورت كه، ابتدا والدين آنها برسشنامهى علائم مرضى كود كان CSI-4 را تكميل نموده و كود كانى كه در هيجيكك از مقياسها حائز نمرهى بالينى نبودند در فرايند بيزوهش قرار گرفتند. ملاككهاى خروج آزمودنىها نيز شامل سابقه ضربه به سر و معلوليت، مشكل در دركى اجراى آزمونهاى رايانهاى با وجود توضيحات و كمككهاى لازم و دريافت نمرهى كمتر از همدر آزمون هوش ريون بود. در نهايت، بِ از حذف دو كودك به دليل ويايين بودن هوشبهر و يكك كودك به دليل همبودى با اختلال اوتيسم، سب كودك كـ ADHD عادى واجد تمامى شرايط حضور براى انجام تكاليف بازدارى و خطريذيرى شدند.

ابز ار يرسشنامه علائم مرضى كودكان (CSI-4)؛ :برسشنامه علائم مرضى كود كان (CSI-4) يكك مقياس درجهبندى

Children Symptom Inventory-4 
در آزمون BART روى صفحه نمايش (مانيتور) رايانه يكك باد كنك نمايش داده مى شود كه در كنار آن د كمه ايى وجود دارد كه هر بار فشردن آن موجب افزايش قطر باد كنك (باد شدن باد كنكs) به اندازه يكك درجه (حدود ץ/ • سانتيمتر ) مىشود. با هر بار باد شدن باد كنك، ينجاه تومان بول به ذخيره يكك صندوق موقتى اضافه مىشود.

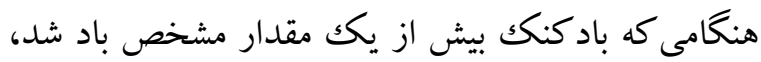
با صداى "ياب)" (يخش از بلندگهوهاى رايانه) تركيده و

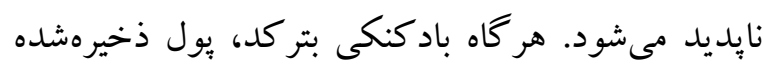
در صندوق موقتى از دست مىرود. شركت كننده مى تواند در هر مرحله آزمون به جاى باد كردن بيشتر بادكنكك با فشردن دكمه ديخرى كه در صفحه نمايش نشان داده شده است، بول ذخيرهشده در صندوق موقتى را به صندوق اصلى منتقل كند. يُ از اين اقدام، باد كنكك باد نشدهى ديخرى در اختيار وى قرار مى گيرد (مجموع باد كنككها در طول آزمون ·r عدد مىباشد). در اين آزمون احتمال تركيدن بادكنك بر اساس انتخاب

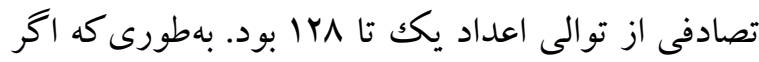

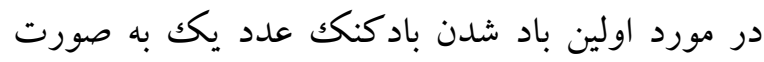

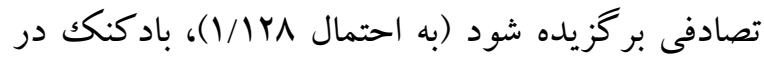
همان مرحله خواهد تركيد. اين احتمال در انتخاب صدوبيستوهشتم، يكك خواهد بود. در بزوهش حاضر، اين آزمون طورى طراحى شده كه باد كردن بادكنك يس از بار ينجاهم ميزان يول دريافتى را به صورت تصاعدى افزايش مىدهد؛ بهطورى كه، هر بار باد كردن باد كنكك پِس از بار بنجاهم، به جاى افزايش "( •ه تومانى"

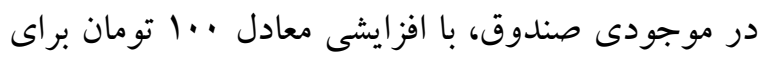
هر باد كردن همر اه خواهد بود كه اين افزايش تا شصتمين مرتبه به همين ميزان است، به همين ترتيب از باد كردن
تكليف رايانهاى برو/نوو (Go-Nogo): اين آزمون به طور وسيعى براى اندازه گيرى بازدارى رفتارى استفاده مىشود (منون، الدمن، وايت، I. Y) و شامل دو دسته محرك است. آزمودنىها بايد به دستهاى از اين محر ككها ياسخ دهند (Go) و از ياسخدهى به دسته ديخر خوددارى كنند (Nogo). ازآنجايى كه تعداد محر ككهاى Go معمولاً بيشتر از محرككهاى Nogo است، آمادگى براى ارائه

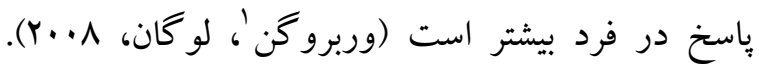
خطاى ارتكاب بالا به معنى انجام بِاسخ حر كتى در هنگگام ارائهى محر كك Nogo بوده و به معناى بازدارى رفتارى ضعيف مىباشد. تعداد محرككهاى Go در اين مطالعه 191 كوشش و تعداد محر كsهاى Vogo

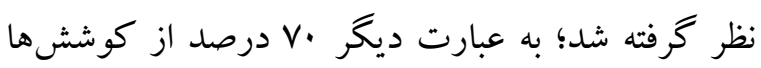
و · · درصد از كوششها (Gogo) ارائهى هر كوشش برابر با . . . هزارم ثانيه بود كه در مجموع تكليف 9 دقيقه و . F. ثانيه طول مى كشيد. در يثزوهش حاضر، نمرات خطاى ارتكاب آزمودنىها، به عنوان شاخصى براى سنجش نقص در بازدارى مورد تحليل و بررسى قرار گرفت. آزمون خطريذيرى بادكنكى: آزمون خطريذيرى

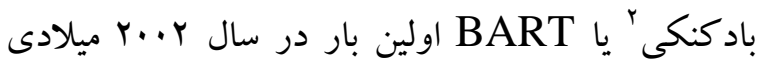
بهوسيله لجوئز معرفى شد. اين آزمون كامييوترى امكان

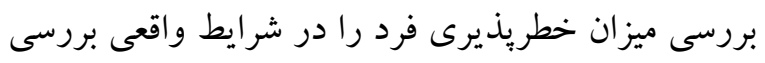
كرده و ميزان كار كرد يا كثز كنشى راهبرد مخاطرهجويانه ى وى را مىسنجد (لجوئز و همكاران، ب...r). آزمون طورى طراحى شده است كه درجات خفيف خطريذيرى سودبخش و با ياداش همراه بوده درحالى كه خطريذيرى

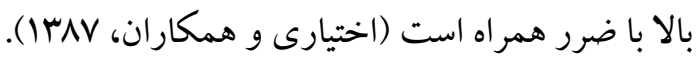


شصت تا هفتاد ·1 ا تومان افزايش، هفتاد تا هشتاد ..

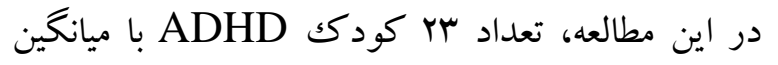

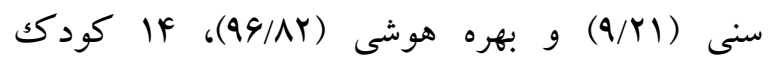
ADHD+CD

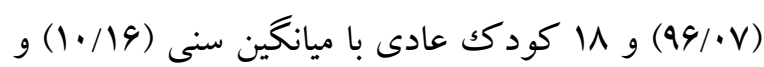
بهره هوشى (س//. - 1) شر كت داشتند. همان گونه كه در جدول ا مشاهده مىشود، بين گروهها از نظر سن (

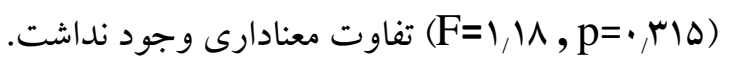

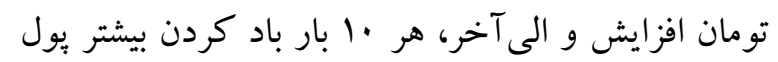
بيشترى را به صندوق موقتى فرد مىافزايد. به اين دليل كه با افزايش احتمال تركيدن بادكنك در باد كردنهاى بالاتر از ينجاه به ياداش بيشترى نياز است تا فرد به ادامهى

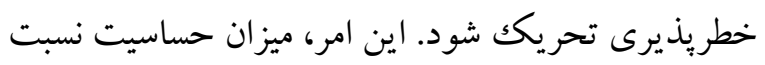
به ياداش در آزمودنى را مورد سنجش قرار مىدهد. علاوه بر اين، ميانگين تعداد باد كردنها در تلاشهاى بعد بعد از تر كيدن بادكنككها به عنوان شاخصى براى سنجش حساسيت منفى نسبت به تنبيه در نظر خرفته شد. در اين آزمون مقادير زير به عنوان نمرات آزمون در نظر

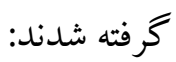
ا. نمره تنظيمشده'؛ معادل ميانگين دفعات بِمبٍ شدن باد كنككهايى است كه نتر كيدهاند. اين متغير، نمره اصلى له آزمون و شاخص خطريذيرى آزمودنى است.

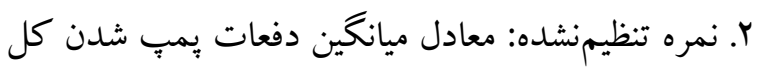
باد كنككها است. r. تعداد باد كنككهايى كه بيشتر از بنجاه مرتبه باد شدهاند: شاخص حساسيت نسبت به ياداش.

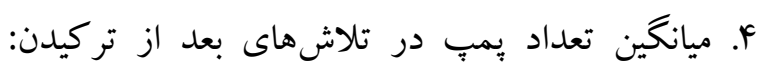
شاخص حساسيت منفى نسبت به تنبيه. دادهاى بدست آمده بهوسيله آزمون تحليل واريانس

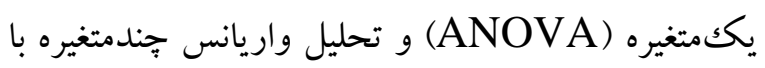

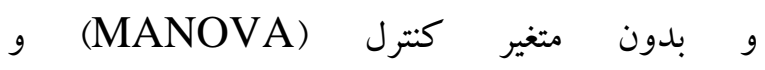
SPSS و با استفاده از نرمافزار (MANCOVA) (نسخه (Y ) مورد تجزيهو تحليل قرار كرفت. 
جدول ا. مقايسه ميانغين سن و هوشبهر در گروههاى موردمطالعه

\begin{tabular}{|c|c|c|c|c|c|c|c|}
\hline معنىدارى سطح & $\mathbf{F}$ & آزادى درجه & ميانكين و انحر اف معيار & $\begin{array}{c}\text { ميانكين و انحر اف } \\
\text { ADيار كروه } \\
\text { ADHD+CD }\end{array}$ & $\begin{array}{l}\text { ميانكين و انحر اف } 2 \text { معروه } \\
\text { ADHD }\end{array}$ & متغير & منبع \\
\hline$\cdot, \wedge 1$ & $r, q r$ & r & $1 \cdot 19 \pm 1,49$ & $1 \cdot, \cdot v \pm 1, q r$ & $Q, Y| \pm|, r \mid$ & سن & كروه \\
\hline • & 1,11 & r & $1 \cdots, r \pm \Lambda, \Delta r$ & $৭ q, V \backslash \pm V, ৭ \varphi$ & $৭ 9, \wedge r \pm \vee, 9 ৭$ & بهره هوشى & كروه- \\
\hline
\end{tabular}

دادههاى مربوط به دو متغير وابسته اصلى شامل استباطى حاصل از تحليل دادههاى شاخصهاى خطريذيرى و خطاى بازدارى به نرمافزار 22 SPS

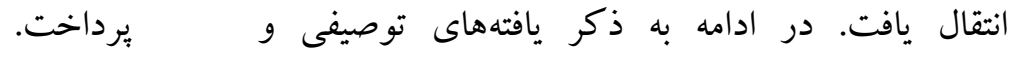

جدول r. ميانتين و انحر اف استاندارد نمرات شاخصهاى خطر يذيرى و خطاى بازدارى در كروههاى موردمطالعه

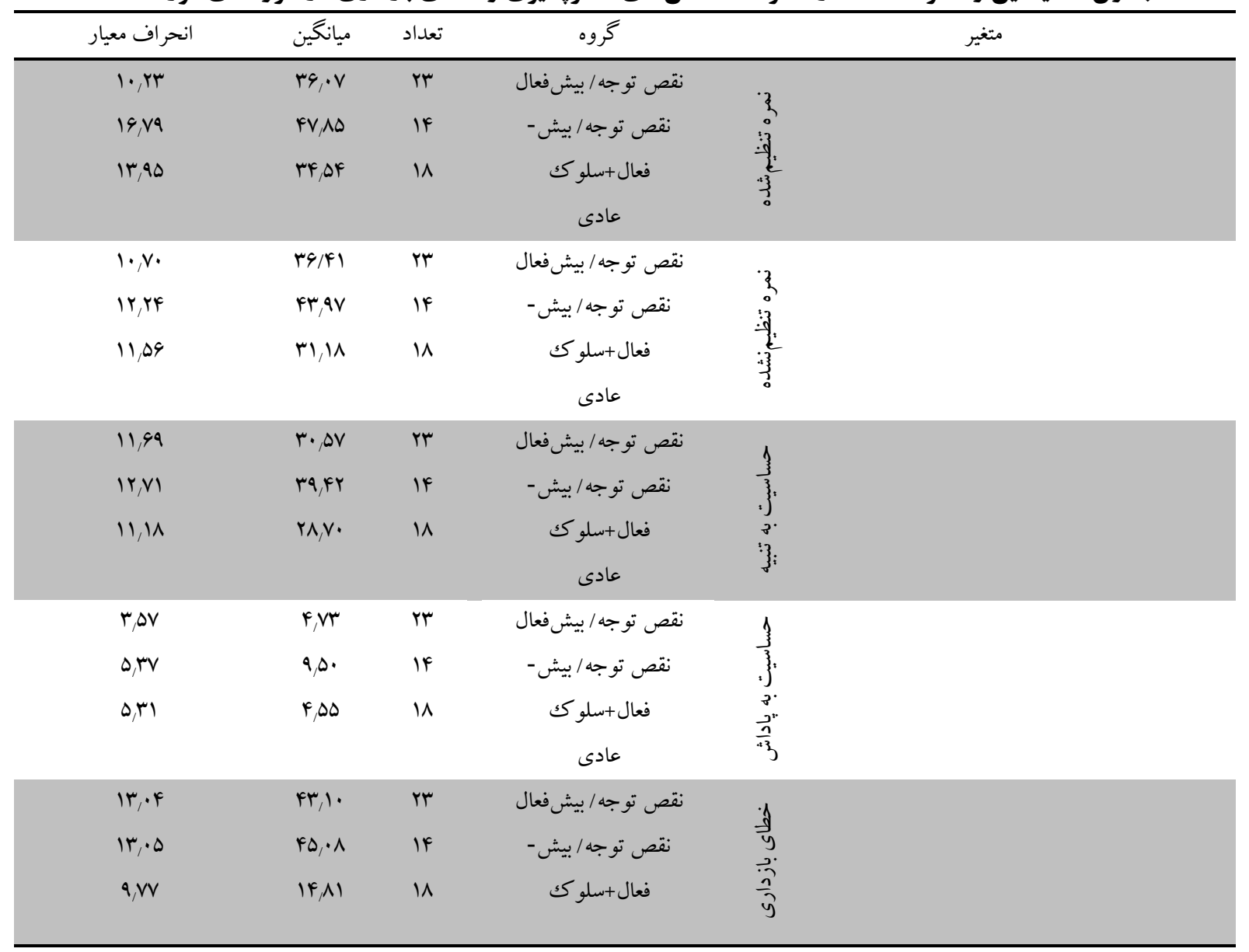


در ادامه، مقايسه زوجى تفاوت بين ميانخين نمرات شاخص خطريذيرى بيش از كنترل نمرات بازدارى نشان مى دهد كه در تمام خردهمقياسهاى خطريذيرى بين دو كروه كود كان ADHD و ADHD+CD معنادار (در سطح ه •, •) وجود دارد، همجنين بين نمرات شاخصهاى خطريذيرى بين كود كان ADHD+CD و عادى تفاوت معنادار وجود دارد، درحالى كه بين كود كان ADHD و عادى اين تفاوت مشاهده نمىشود (جدول

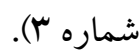

براى بررسى تفاوت نمرات خطاى بازدارى در سه گروه از آزمون تحليل واريانس استفاده شد كه با توجه به

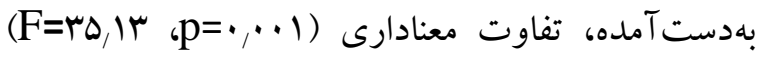
بين عملكرد گروهها وجود داشت. نتايج تحليل واريانس، نشان داد كه بيش از كنترل خطاى بازدارى، تفاوت معنادارى (در سطح ه•,.) در متغير تر كيبى شاخص هاى خطريذيرى (خطريذيرى، حساسيت به بِاداش و حساسيت منفى به تنبيه) بين سه كروه وجود دارد (r)

جدول r. مقايسه زوجى ميانتينهاى نمرات زير مقياسهاى خطريذيرى ييش از كنترل خطاى بازدارى در سه كروه ADHD+CD ،ADHD

\begin{tabular}{|c|c|c|c|c|c|}
\hline معنادارى & تفاوت بين ميانكينها & عادى & ADHD+CD & ADHD & شاخص \\
\hline$\cdot \cdot 1$ & $-11, \Delta r$ & - & $F V / \wedge \Delta$ & $r q, \cdot v$ & نمره تنظيمشده \\
\hline$\cdot, \mathrm{VII}$ & $r, 9$ & $\mu F, \Delta F$ & - & $r q, \cdot v$ & \\
\hline,., 4 & $9 \Delta r$ & $\mu F \Delta F$ & $F V, \wedge \Delta$ & - & \\
\hline.,$\cdot F r$ & $-V, \mu)$ & - & $k r, q \mathrm{~V}$ & $r a, 41$ & نمره تنظيمنشده \\
\hline$\cdot, 114$ & F,A9 & $r, 11$ & - & $r q, 41$ & \\
\hline,$\ldots 1$ & $1 \cdot, k Y$ & $\mu, 1 \mu$ & $k r, q v$ & - & \\
\hline$\cdot, \cdot r$ & $-\Lambda_{1} \mu^{\mu}$ & - & $r q, F r$ & $r \cdot \Delta V$ & حساسيت منفى به تنبيه \\
\hline., 919 & $1, A V$ & $r \wedge, V$. & - & $r \cdot \Delta V$ & \\
\hline., .14 & $p, p q$ & $r \wedge, V$. & $r q, k r$ & - & \\
\hline$\because, r F$ & $-F, V F$ & - & $q, \Delta$. & $r, k$ & حساسيت به پاداش \\
\hline$\cdot 9 \cdot 1$ & $\cdot,+4$ & $F, \Delta \Delta$ & - & r,Nr & \\
\hline$\cdots \cdots$ & $r, 99$ & $F, \Delta \Delta$ & $9, \Delta$. & - & \\
\hline
\end{tabular}

نتايج تحليل واريانس نشان داد كه بِ از كنترل خطاى به باداش و حساسيت منفى به تنبيه) بين سه گروه وجود

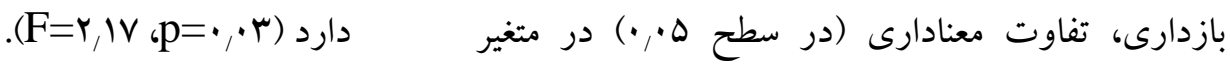
تر كيبى شاخصهاى خطريذيرى (خطريذيرى، حساسيت 
معنادار (در سطح ه•,•) وجود دارد، اين درحالى|ست كه بين ساير گروهها تفاوت معنادارى مشاهده نمىشود

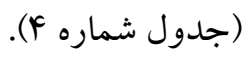

مقايسه زوجى تفاوت بين ميانگين نمرات شاخص خطريذيرى بِ إز كنترل نمرات بازدارى نشان مىدهد كه در تمام خردهمقياسهاى خطريذيرى هميجنان بين دو كروه كودكان ADHD و ADHD+CD

جدول †. مقايسه زوجى ميانكينهاى نمرات زيرمقياسهاى خطر بذيرى بِ از كنترل خطاى بازدارى در سه كروه ADHD+CD ،ADHD و عادى

\begin{tabular}{|c|c|c|c|c|c|}
\hline معنادارى & تفاوت بين ميانكينها & عادى & ADHD+CD & ADHD & شاخص \\
\hline., 14 & $-11, \Delta r$ & - & $F V / \wedge D$ & $\mathrm{rq} \cdot \mathrm{V}$ & نمره تنظيمشده \\
\hline - VYG & $r, \cdot 9$ & rF $\Delta F$ & - & $\mathrm{rq}, \mathrm{V}$ & \\
\hline$\cdot, Q P F$ & $9, \Delta r$ & MF, DF & $F \vee \wedge \Delta$ & - & \\
\hline$\cdot, \cdot 4 \Lambda$ & $-V, F i$ & - & $\mathrm{Fr}, \mathrm{qV}$ & re,pl & نمره تنظيمنشده \\
\hline · $\Delta \mu_{q}$ & $\varphi \wedge q$ & $M, 1 \wedge$ & - & $|4,4\rangle$ & \\
\hline$\because \cdot \Delta V$ & $1 \cdot, k r$ & $m, 11$ & $F r, q V$ & - & \\
\hline$\cdot \bullet \mu \wedge$ & $-\Lambda, F F$ & - & $r q, F r$ & $r \cdot \Delta v$ & حساسيت منفى به تنبيه \\
\hline,,$f \Delta \Lambda$ & $1, \wedge \mathrm{V}$ & $r \wedge, V \cdot$ & - & $r \cdot \Delta V$ & \\
\hline$\cdot|F F|$ & $f, F q$ & $r \wedge, \gamma \cdot$ & rq, fr & - & \\
\hline$\because \cdots \Delta$ & $-f, V F$ & - & $q, \Delta$. & $r, v r$ & حساسيت به پاداش \\
\hline$\cdot 91 \mathrm{r}$ & $\cdot,+\wedge$ & $\varphi \Delta \Delta$ & - & $k, v r$ & \\
\hline., 01 & 4,99 & $f, \Delta \Delta$ & $9 / \Delta$. & - & \\
\hline
\end{tabular}

بازدارى به طور معنادارى بالاتر بود. يعنى متغير

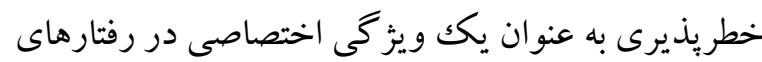

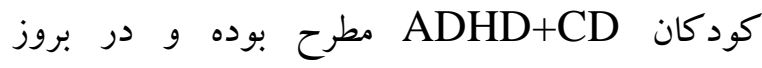
رفتارهاى سازشنايافته در اين كودكان نقش بيشينىكنندهترى دارد.

نتايج آمارى بدست آمده نشان داد كه بين سه كروه كود كان ADHD+CD ADHD و و كودكان عادى بس از كنترل خطاى بازدارى تفاوت معنادارى در شاخص هاى خطريذيرى وجود دارد؛ اين تفاوت در گرووه ADHD+CD
به طور خلاصه، نتايج نشان مىدهد كه ميانگين نمرات شاخصهاى خطريذيرى بين گروه ADHD و عادى در سطح تقريباً يكسانى قرار داشته، با و بدون كنترل نمرهى ئرئ خطاى بازدارى نيز معنادار نيست. اما نمرات خطريذيرى برى كود كان ADHD+CD ييش از كنترل نمرهى خطاى بازدارى به طور معنادارى بالاتر از گروه عادى بود كه يس از كنترل خطاى بازدارى اين معنادارى مشاهده

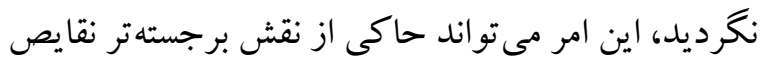
Aازدارى در رفتارهاى يرخطر كود كان Aان

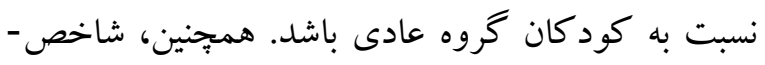
هاى خطريذيرى در كود كان ADHD+CD در مقايسه

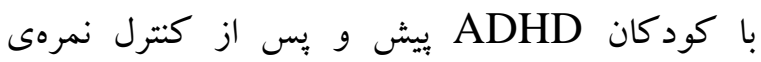


احتمال آسيب به خود يا ديخران را افزايش مىدهد؛ درحالى كه، گرايش به خطريذيرى مى تواند به عنوان يكى از عوامل زمينهساز در بروز رفتارهاى برخطر نقش آفرينى كند اما نه بهتنهايى. عوامل ديخرى از جمله رمله ("تصميم گيرى در شر ايط عاطفى)، (ضعف در مهارتهاى

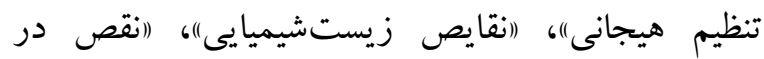
ادراكك زمان)، (اكيفيت روابط والد-فرزند)،، (اسبكهاى فرزنديرورى") و (نقش گروه دوستان) همخى در بروز

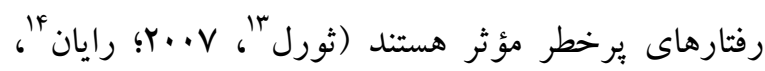

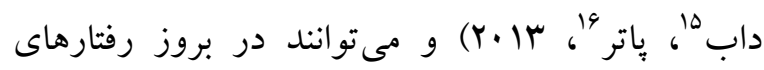
سازشنايافته و مخاطرهجويانه در كودكان ADHD نقش داشته باشند؛ بنابراين، مىتوان نتيجه گرفت كه رفتار يرخطر در ADHD صرفاً حاصل گر ايش به خطريذيرى بالا نبوده و تابعى از كليه عوامل ذكرشده است. همجينين،

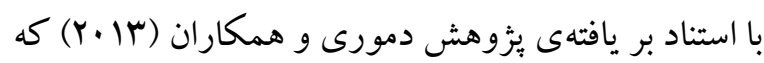
نشان دادند عملكرد بازدارى رفتارى در كودكان ADHD

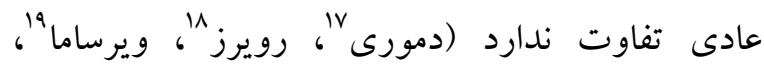

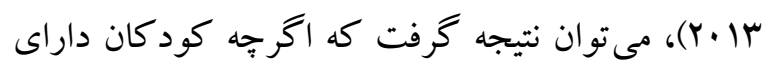
علائم ADHD رفتار تكانشخرانه از خود بروز مىدهند، اما در موقعيتهايى كه تصميم گيرى با درجاتى از سود همراه باشد، مىتوانند بِاسخهاى خود را بازدارى نمايند.

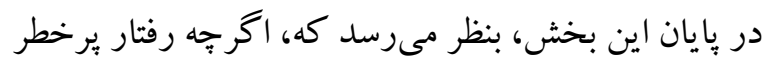
يكى از نشانهاى اصلى در ADHD بهخصوص در بن بحر سنين نوجوانى است، اما اين كه بروز اين رفتارها را تماماً
عادى وجود داشته، درحالى كه تفاوت معنادارى بين عملكرد كود كان ADHD و عادى مشاهده نشد. يافتهاى فوق از جند منظر قابلتبيين و نتيجه گيرى است كه در ادامه به ذكر و بررسى آنها خواهيم يرداخت. در بخش اول، نتايج يخوهش حاضر نشان مىدهد كه بين كود كان ADHD و عادى، "إيش و و يس از كنترل خطاى بازدارى" تفاوت معنادارى در شاخصهاى خطريذيرى وجود ندارد. در نغاه اول شايد اين يافته نامأنوس و غيرمعمول به نظر برسد، جراكه به گُواهى

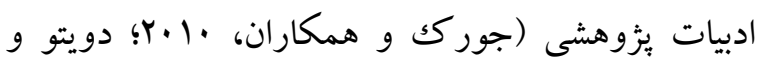

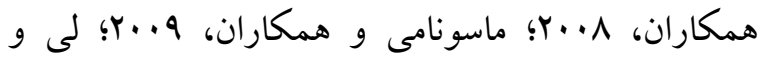

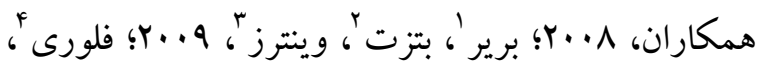

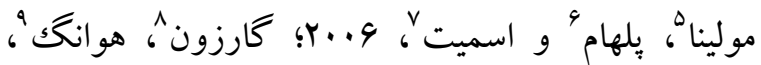

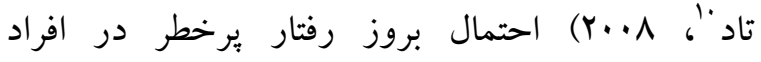
بDHD ظريفى وجود دارد كه مىتواند نتايج حاصل در يثوهش حاضر را توجيه و تبيين نمايد. نكته اول تمايزى است كه بايستى بين دو عبارت "اكرايش به خطريذيرى" "ه و و "اعمال

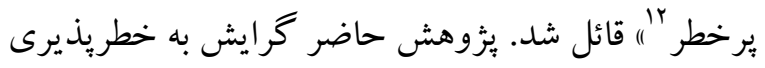
را مورد سنجش قرار داده است در حالى كه تمركز اصلى در ادبيات يُزوهشى بر اعمال و رفتارهاى برخطر (از جمله سوءمصف مواد، رفتار جنسى آشوبناك، سوانح رانندگى و...) در بين افراد با سابقهى ADHD است. درواقع، رفتار برخطر شامل كليه فعاليتهايى است كه

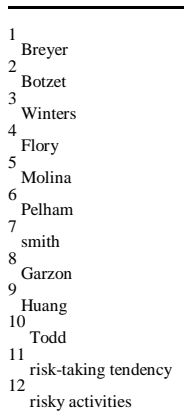


r. زمانى كه نشانهاى فوق با خطريذيرى بالا همر اه شود، احتمال بروز نشانهاى اختلال سلوكك (CD) افزايش

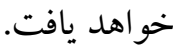

با توجه به موارد مطرحشده به نظر مىرسد كه نقص در بازدارى و اختلال نارسايى توجه/ بيشفعالى مىتوانند عوامل زمينهسازى براى بروز اختلال سلو كك باشند، اما بهتنهايى كافى نيستند. با توجه به نتايج بزوهش حاضر، خطريذيرى مىتواند به عنوان يك عامل برانگيزاندهه براى اختلال سلو كك در نظر گرفته شود. به عبارت ديخر، ADHD بروز CD شوند كه توسط عامل خطريذيرى تقويت شده باشند. يزووهش هاى آتى مىتواند به تائيد بيشتر اين فرضيه

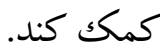

\section{References}

Alderson, R. M., Rapport, M. D., \& Kofler, M. J. (2007). Attention-deficithyperactivity disorder and behavioral inhibition: A meta-analytic review of the stop-signal paradigm. Journal of Abnormal Child Psychology, 35, 745-758.

Alizadeh, Hamid. (2005). Theoretical explanation of attention deficithyperactivity disorder: behavioral inhibition pattern and self-control nature. Research on Exceptional Children, Fall, Vol.17, No.3, (323348) (Persian).

American Psychiatric Association. (2013). Diagnostic and Statistical Manual of Mental Disorders DSM5.American Psychiatry pub.

Bari A, Robbins TW. ( 2013). Inhibition and impulsivity: behavioral and neural basis of response control. Progress in neurobiology. Sep 30; 108:44-79.
حاصل گرايش به خطريذيرى بالا بدانيم كمى دور از ذهن به نظر مىرسد. بخش ديخر يافتهاى بزّوهش حاضر نشان مىدهد كه بين كود كان ADHD و ADHD+CD ييش و و يس از كنترل اثر خطاى بازدارى تفاوت معنادارى در شاخصهاى خطريذيرى وجود دارد كه اين يافته اطلاعات ارزشمندى در سير ADHD به CD بدست مىدهد. در تبيين اين يافته مباحث جالبى قابلبحث و تبيين بوده كه در ادامه به ذكر آنها خواهيم برداخت:

خصايص ضداجتماعى يكى از مباحثى است كه ارتباط آن با ريسككيذيرى به اثبات رسيده است (سنتيفانتى'

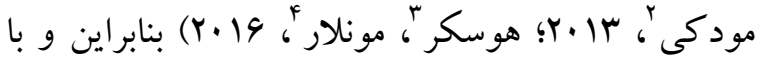
با توجه به اين كه خصايص ضداجتماعى در سير اختلال سلو كك مشاهده مىشود، وجود احتمالى اين خصايص در كودكان CD را مىتوان به عنوان عامل تمايز بين كودكان ADHD و ADHD+CD در خطريذيرى، حساسيت به ياداش و حساسيت منفى نسبت به تنبيه به

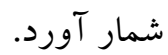

\section{نتيجه كيرى}

1. اختلال نارسايى توجه / بيش فعالى با نقص در بازدارى

$$
\text { رفتارى همراه است. }
$$

r. تر كيب اين دو عامل مى تواند رفتارهاى تكانشگرانه را به همراه داشته باشد، ولى بهتنهايى منجر به نشانهاى اختلال سلو كك نمىشوند. 
Barkley, R.A. (1997). Behavioral inhibition, sustained attention, and executive functions: constructing a unifying theory of ADHD. Psychological Bulletin. 121, 65-94.

Bjork, J. M., Smith, A. R., Chen, G., \& Hommer, D. W. (2010). Adolescents, adults and rewards: comparing motivational neurocircuitry recruitment using $\mathrm{AMRI}$. Plos one, 5(7), e11440.

Boonstra, A. M., Kooij, J. J., Oosterlaan, J., Sergeant, J. A., \& Buitelaar, J. K. (2010). To act or not to act, that's the problem: Primarily inhibition difficulties in adult ADHD. Neuropsychology, 24(2), 209.

Breyer, J. L., Botzet, A. M., Winters, K. C., Stinchfield, R. D., August, G., \& Realmuto, G. Young. (2009). adult gambling behaviors and their relationship with the persistence of $\mathrm{ADHD}$. Journal of Gambling Studies, 2, 227-238.

Centifanti (ne Muoz), L.C. and Modecki, K. L (2013). Throwing caution to the wind: callousunemotional traits and risk-taking in adolescents. Journal of clinical child and adolescent psychology, 42(1) 106-119.

Demurie, E., Roeyers, H., Wiersema, J. R., \& SonugaBarke, E. (2013). No Evidence for Inhibitory Deficits or Altered Reward Processing in ADHD: Data from a New Integrated Monetary Incentive Delay Go/No-Go Task. Journal of attention disorders, 1087054712473179.

DeVito, E. E., Blackwell, A. D., Kent, L., Ersche, K. D., Clark, L., Salmond, C. H., etal. (2008). The effects of methylphenidate on decision making in attention-deficithyperactivity disorder. Biological Psychiatry, 64, 636-639.

Daugherty, T. K., Quay, H. C., \& Ramos, L. (1993). Response perseveration, inhibitory control, and central dopaminergic activity in childhood behavior disorders. The Journal of Genetic Psychology, 154(2), 177-188

Ekhtiari, H., Rezvanfard, M. and Mokri, A. (2008). Impulsivity and its different assessment tools: A review of viewpoints and conducted researches. Iranian Joumal of Psychiatry and Clinical Psychology, 14(3), pp.247-257.

Ekhtiari, Hamed; Jannati; Ali; Moghimi; Amir; Behzadi; Arian. (2000). Introducing the Persian version of the Balloon Analog Risk Task: A
Toolkit for Behavioral Risk Assessment, Journal of Cognitive Science Reflections, (4) 4, 37-49. (Persian)

Flory, K., Molina, B. S. G., Pelham, W. E., Gnagy, E., \& Smith, B. (2006). Childhood ADHD predicts risky sexual behavior in young adulthood. Journal of Clinical Child and Adolescent Psychology, 35, 571-577.

Garzon, D. L., Huang, H., \& Todd, R. D. (2008). Do attention deficit/ hyperactivity disorder and oppositional defiant disorder influence preschool unintentional injury risk? Archives of Psychiatric Nursing, 22, 288-296.

Harnishfeger, K. Dempster, F., Brainerd, C. (Eds.), (1995). Development of cognitive inhibition. Interference and Inhibition in Cognition. Academic Press, New York.

Hosker-Field, A. M., Molnar, D. S., \& Book, A. S. (2016). Psychopathy and risk taking: Examining the role of risk perception. Personality and Individual Differences, 91, 123-132.

Humphreys, K. L., \& Lee, S. S. (2011). Risk taking and sensitivity to punishment in children with $\mathrm{ADHD}$, ODD, ADHD+ ODD, and controls. Journal of Psychopathology and Behavioral Assessment, 33(3), 299-307.

Jessor, R. (1998). New perspectives on adolescent risk behavior. Cambridge, England: Cambridge University Press.

Lee, S. S., Lahey, B. B., Owens, E. B., \& Hinshaw, S. P. (2008). Few preschool boys and girls with $\mathrm{ADHD}$ are well-adjusted during adolescence. Journal of Abnormal Child Psychology, 36, 373383.

Lejuez CW, Aklin WM, Zvolensky MJ, Pedulla CM. (2003). Evaluation of the Balloon Analogue Risk Task (BART) as a predictor of adolescent realworld risk-taking behaviors. Journal of Adolescence. 26:475-479.

Lijffijt, M., Kenemans, J. L., Verbaten, M. N., \& van Engeland, H. (2005). A meta-analytic review of stopping performance in attentiondeficithyperactivity disorder. Deficient inhibitory motor control? Journal of Abnomal Psychology, 114(2), 216-222. 
Loeber, R., Burke, J. D., Lahey, B. B., Winters, A, \& Zera, M. (2000). Oppositional defiant and conduct disorder: a review of the past 10 years, part I Joumal of the American Academy of Child \& Adolescent Psychiatry, 39(12), 1468-1484.

Menon, V., Adleman, N.E., White, C.D., Glover, G.H., Reiss, A.L. (2001). Error-related brain activation during a Go/NoGo response inhibition task. Human Brain Mapping.12, 131-143.

Masunami, T., Okazaki, S., \& Maekawa, H. (2009). Decision-making pattems and sensitivity to reward and punishment in children with attentiondeficit hyperactivity disorder. International Journal of Psychophysiology. 72, 283-288.

Mohammad Esmail, Elaheh. (2004). Adaptation and standardization of Child Symptom Inventory (CSI-4). Exceptional Children Research, 7 (1) 7996. (Persian)

Nejati V, Shiri E. (2013). Neurocognitive evidence for deficit in inhibitory control and risky decision making in smokers. J Res Behav Sci; 11(1): 1-9 (Persian)

Nigg, J.T. (2000). On inhibition/disinhibition in developmental psychopathology: views from cognitive and personality psychology and a working inhibition taxonomy. Psychological Bulletin. 126, 220-246.

Nigg, J.T. (2005). Neuropsychologic theory and findings in attention-deficithyperactivity disorder: the state of the field and salient challenges for the coming decade. Biological Psychiatry. 57, 1424 1435.

Oosterlaan, J., Logan, G. D., \& Sergeant, J. A. (1998). Response inhibition in $\mathrm{AD} / \mathrm{HD}, \mathrm{CD}$, comorbid $\mathrm{AD} / \mathrm{HD}+\mathrm{CD}$, anxious, and control children: A meta-analysis of studies with stop task. Journal of Child Psychology and Psychiatry, 39(3), 411-425.

Patros CH, Alderson RM, Kasper LJ, Tarle SJ, Lea SE, Hudec KL. (2016 ). Choice-impulsivity in children and adolescents with attentiondeficithyperactivity disorder (ADHD): A metaanalytic review. Clinical psychology review. Feb 29; 43:162-74.

Rabiee, N., DOLAT, S. B., \& Bagheri, F. (2011). Comparison of Inhibition in School-Aged Children with Conduct Disorder and Normal Group. (Persian).

Ryan KK, Dube SL, Potter AS. (2013). Rate dependent effects of acute nicotine on risk taking in young adults are not related to $\mathrm{ADHD}$ diagnosis. Pharmacology Biochemistry and Behavior. Jan 31;103 (3):652-8.

Scheres, A., Oosterlaan, J., \& Sergeant, J. A. (2001). Response inhibition in children with DSM-IV subtypes of $\mathrm{AD} / \mathrm{HD}$ and related disruptive disorders: the role of reward. Child Neuropsychology, 7(3), 172-189.

Thorell, L. B. (2007). Do delay aversion and executive function deficits make distinct contributions to the functional impact of ADHD symptoms? A study of early academic skill deficits. Journal of Child Psychology and Psychiatry, 48(11), 1061-1070.

Verbruggen, F., Logan, G.D. (2008). Response inhibition in the stop-signal paradigm. Trends in Cognitive Sciences. 12, 418-424. 